\title{
Cómo John y Yoko aplican los valores Ibero en su vida
}

\section{How John and Yoko Apply Ibero Values in their Lives}

\author{
José Antonio Farias Hernández \\ Universidad Iberoamericana Ciudad de México, México \\ jose.farias@ibero.mx
}

https://doi.org/10.48102/didac.2022..79_ENE-JUN.96

3

\begin{abstract}
RESUMEN
La Universidad Iberoamericana busca formar a la persona completa. Los cuatro componentes básicos de su pedagogía ignaciana son la utilidad, la promoción de la justicia, la formación humanista y la vivencia de la fe. El Taller de Servicio Social es un espacio ideal para reforzar los valores contenidos en esos componentes al momento de egresar. Este artículo narra una experiencia exitosa en la transmisión de los valores de la educación jesuita en la Universidad Iberoamericana, como un legado vivo y operante. Para esto, se diseńó un módulo basado en la educación sentimental y la metodología del taller en la educación popular, por medio del rock como comunicación e identidad entre jóvenes universitarios. El caso de John Lennon y Yoko Ono resultó en ensayos muy personales, profundos y dirigidos hacia un entusiasta compromiso con temas como la solidaridad, la paz, la equidad de género, la libertad y la excelencia profesional. Todo esto con posibilidad de replicarse en otros ambientes y con las figuras de referencia que cada participante elija.
\end{abstract}

Palabras clave: Pedagogía ignaciana; servicio social; Taller de Servicio Social; formación social; valores.

\section{Abstract}

The Universidad Iberoamericana seeks to train every student in an integral way. The four basic components of his Ignatian Pedagogy are usefulness, the promotion of justice, humanistic formation, and the living offaith. The social service workshop is an ideal space to reinforce the values contained in these components at the time of graduation. This article narrates a successful experience in transmitting the values of the Jesuit education at the Universidad Iberoamericana as a living and operating legacy.

In order to achieve this, a module was designed based on sentimental education and the methodology of the workshop in popular education, through rock music as communication and identity among young university students. The case of John Lennon and Yoko Ono resulted in very personal, in-depth and derivative essays towards an enthusiastic commitment to topics such as solidarity, 
peace, gender equality, freedom, and professional excellence. All of this with the possibility of being replicated in other environments and with the reference figures that each one chooses.

Keywords: Ignatian Pedagogy; Social Service Workshop; Social Service; Social Training; Values.

Fecha de recepción: 20/06/2021

Fecha de aceptación: 26/08/2021

\section{El Taller de Servicio Social y los valores Ibero}

Desde hace 50 años, en la Universidad Iberoamericana el servicio social tiene valor curricular en la materia Taller de Servicio Social, beneficio que muy pocas universidades de México han logrado. Este gran paso se dio en la década de los setenta, a partir de las llamadas "experiencias de verano", que incluían momentos de reflexión en grupo. En la década de los ochenta se implementó como taller, lo cual introdujo a nuestra casa de estudios en el medio universitario del país, después de experimentarlo con grupos y movimientos urbanos populares. Para Andrade (2001) el Taller de Servicio Social es un espacio de reflexión colectiva con enfoque humanista e interdisciplinario, que aporta al estudiante elementos prácticos y conceptuales para el análisis de los problemas sociales de México, generando crítica, propuesta y responsabilidad social (pp. 29-30).

El Taller de Servicio Social es parte de la formación integral y constitutiva del modelo educativo Ibero, y se fundamenta en la parte del Ideario que habla de infundir en el estudiantado

una conciencia viva y operante de los problemas sociales de México, y la consecuente responsabilidad de cooperar a resolverlos, [procurando a la vez] un contacto directo del estudiante con la realidad del país, y establecer como parte del currículum de estudios un servicio social auténtico en bien de la comunidad. (Universidad Iberoamericana Ciudad de México, 1968, p. 4).

En la actualidad el taller forma parte del plan de estudios de todas las carreras con un valor de 16 créditos, y se basa en el proceso contexto-experiencia-reflexión-acción-evaluación de la pedagogía ignaciana. Se cursa a la par de la praxis del servicio social en alguno de los dos últimos semestres, y es la culminación de una formación social espaciada a lo largo de la carrera.

Tiene una parte práctica, que consiste en observar el cumplimiento del servicio social del estudiantado, y desde luego una parte reflexiva fundamental. Quien la imparte es el "asesor de servicio social". Su parte formativa se enfoca en exponer y debatir en el aula las experiencias de servicio social en grupos multidisciplinarios, alrededor de alguna de las problemáticas sociales que la Ibero ha definido para tematizar tanto los proyectos de las instituciones vinculadas (predominantemente del tercer sector), como los grupos de reflexión: derechos humanos y ciudadanía; salud y atención integral; medio ambiente; discapacidad y vejez; educación inclusiva; economía social y solidaria; desarrollo comunitario; y cultura y medios de comunicación. En su parte medular, el taller se resuelve con un ensayo-exposición sustentado en una investigación del diagnóstico sobre la problemática social específica del servicio social de cada estudiante: macro, en México y el mundo; y micro, en el ámbito de la institución donde el estudiante realiza su servicio social. Por ejemplo, en el área de derechos humanos y ciudadanía, el tema macro puede ser "refugiados que entran por la frontera sur", y el micro, "ACNUR". Dicho diagnóstico sustenta la exposición y el debate de las experiencias. A partir de esto, durante el semestre el docente complementa con los temas sociales que libremente elija: actualidad nacional; asuntos transversales, como pobreza, sustentabilidad, género; $y$, desde luego, todos aquellos que nutran a su área.

En mi caso como asesor de servicio social, el método que utilizo consiste en hacer del taller una comunidad de debates de altura universitaria (argumentar con narrativas académicas), con respeto al 
otro, libertad de expresión y expresividad (para animar a escribir y verbalizar a los estudiantes de carreras que no suelen cultivar la palabra, como por ejemplo, diseños, nutrición e ingenierías) y con equidad y democracia académica, en el sentido de considerar al estudiante en fase terminal de su carrera como alguien con ideas sociales bien afirmadas, así como el hecho de que ninguna carrera está por encima de otra en sus apreciaciones sobre la sociedad. Bajo esta resolución del taller, el docente es un pensador en equidad de opinión, quien simplemente acumula más conocimientos y tiene experiencia en facilitar el debate multidisciplinar y llevarlo a algunas generalizaciones teóricas.

Uno de los temas que exploro con los estudiantes parte de la siguiente pregunta: ¿cuánto gané y cuánto perdí habiendo estudiado en la Ibero?, cuestión que permite derivar de manera casual los valores de nuestra universidad. Aquí surge otra pregunta: ¿por qué tematizar los valores Ibero si el Taller de Servicio Social es una materia terminal que los supone asimilados? La primera razón es que el estudiantado suele llegar a este taller intuyendo los valores de manera fragmentada. La segunda, más importante por motivos pedagógicos, es mi consideración de que el estudiante debe salir de la Ibero reafirmando su sentido de pertenencia a una tradición educativa en que los valores profesionales, humanistas y sociales son esenciales y, sobre todo, con la disposición de accionarlos en el día a día. Esto en el marco de mi postura sobre el taller a la hora de tratar los problemas sociales de México: ir de manera radical a lo más actual.

Vayamos ahora a los valores universitarios jesuitas y cómo la Ibero los asume, a partir de dos narrativas procesadas en versión libre: las de los extintos Superiores Generales de la Compañía de Jesús Pedro Arrupe y Peter Hans Kolvenbach, así como la concreción contextualizada de esas líneas estratégicas en nuestra universidad.

En la página web Jesuitas. Provincia argentinouruguaya (2019) se cita la charla de 1979 de Arrupe con los jesuitas de México llamada "Universidad y educación jesuítica hoy": la necesidad de promover una transformación en las universidades que fermente la formación de los alumnos como "hombres para los demás", para que sean agentes multiplicadores de cambio; una transformación sustentada en la investigación sobre los problemas humanos y de la realidad social como "apostolado intelectual" al servicio del pobre y por la justicia.

De Kolvenbach sintetizamos su horizonte valoral-pedagógico a partir de cinco narrativas referidas en este mismo sitio web: la universidad debe ser una fuerza social en favor de la justicia, sustentada en el uso de valores como parte de una enseñanza integral. Él asume el llamado paradigma pedagógico ignaciano como el camino práctico para el conocimiento y transformación de la realidad, personal y social, con los ya citados cinco momentos del proceso educativo: contexto, experiencia, reflexión, acción y evaluación. El "por qué" de la universidad es el magis —el máximo de capacidades—, mientras el "para qué" es la persona completa: consciente, compasiva, competente y comprometida, fórmula conocida como las cuatro $C$ de Kolvenbach. También contribuye a que el egresado se forme como una persona práctica-profesional, cívica-social, humanista y religiosa, para que llegue al fin a sus cuatro latinismos que definen a la educación universitaria jesuita: utilitas, iustitia, humanitas y fides.

Ahora bien, este conjunto de características aparece en el modelo educativo Ibero como utilidad, promoción de la justicia, formación humanista y vivencia de la fe. La formación humanista asimila las cuatro $C$ de Kolvenbach, mientras la vivencia de la fe precisa que "todo ser humano lleva en sí una potencialidad que le trasciende y que siempre puede desarrollarse y crecer" (Universidad Iberoamericana Ciudad de México, s. f., p. 3).

Llegamos así al texto en la página web de la Universidad Iberoamericana Ciudad de México llamado Modelo educativo jesuita, con su definición:

La Universidad Iberoamericana es una institución confiada a la Compañía de Jesús, cuya mi-

Cómo John y Yoko aplican los valores Ibero en su vida $\bullet 23$ José Antonio Farías Hernández. DIDAC 79 (2022): 21-28 
sión es contribuir al logro de una sociedad más libre, solidaria, justa, incluyente, productiva y pacífica, mediante el desarrollo y la difusión del conocimiento y la formación de profesionistas e investigadores de gran calidad humana e intelectual, competentes a nivel internacional, comprometidos en el mayor servicio a los demás, e inspirados por valores auténticamente humanos, sociales y trascendentes. (s. f., p. 1).

Ahí mismo se enumeran nuestros valores:

1. Amor, en un mundo egoísta e indiferente. 2. Justicia, frente a tantas formas de injusticia y exclusión. 3. Paz, en oposición a la violencia. 4. Honestidad, frente a la corrupción. 5. Solidaridad, en oposición al individualismo y la competencia. 6. Sobriedad, en oposición a un mundo basado en el consumismo. 7. Contemplación y gratuidad, en oposición al pragmatismo y utilitarismo. (Universidad Iberoamericana Ciudad de México, s. f., pp. 7-8).

Este conjunto se enriquece con dos valores más en el Plan estratégico rumbo 2030: “1. Verdad, como algo propio de la realidad, que pretendemos alcanzar y servir; 2. Libertad, que posibilita la expresión total del ser humano" (Universidad Iberoamericana Ciudad de México-Tijuana, s. f., p. 15).

Finalmente, para completar nuestro horizonte valoral, en la presentación de los nuevos planes de estudio, llamados Manresa, Sylvia Schmelkes señala estos tres ejes transversales de la Ibero para hacer frente al futuro: "1. Interculturalidad. 2. Sustentabilidad. 3. Género" (Universidad Iberoamericana Ciudad de México, 2021).

\section{El ensayo Valores Ibero en John y Yoko}

En cuanto a los fundamentos, para la idea de transmitir valores en el Taller de Servicio Social nos basamos en la educación sentimental. Para Rorty (1998)

este tipo de educación familiariza a personas de distintas clases de suerte que estén menos tenta- das a pensar en los otros como cuasihumanos. El propósito de esta manipulación de sentimientos es ensanchar la referencia de los términos "nuestra clase de gente" y "gente como nosotros" [...]. Las semejanzas no se refieren a un yo profundo y compartido que entrañaría la verdadera humanidad, sino a esas pequeñas y superficiales similaridades, como abrazar a nuestros padres y a nuestros hijos. (pp. 126-132).

Por otro lado, de la metodología de Taller en la Educación Popular podemos extraer la idea de partir "del conocimiento de las personas participantes, sus intereses, historia, códigos culturales y comunicacionales" (Cano, 2012, p. 40). En nuestro caso, el rock representa un poderoso código comunicacional en la cultura juvenil universitaria. Con el rock se pueden identificar y comunicar como parte del mismo grupo cultural un joven que lo fue en 1960 con uno que lo es hoy. Esto se refuerza con la idea de "clásico" — los Beatles lo son-, el cual para Gadamer (1977) es

una verdadera categoría histórica porque es algo más que el concepto de una época o el concepto histórico de un estilo, sin que por ello pretenda ser un valor suprahistórico. [...] una especie de presente intemporal que significa simultaneidad con cualquier presente. (pp. 356-357).

La idea del ensayo de John y Yoko para asimilar los valores Ibero, no de manera mecánica sino como una postura o disposición ante la vida profesional, no fue mera ocurrencia. Casi desde que empecé con el taller hace 20 años me apoyaba intuitivamente en Lennon para la cuestión de luchar por un mundo mejor —en paz, amoroso y más justo-. Esto maduró con otros temas lennonianos —activismo, libertad, crecimiento personal- hasta que mi investigación se concretó hace poco en el texto San John Lennon: el Maestro en el cielo eterno del rock, un ensayo biográfico que lo aborda como persona integral. Ahí se revela un Lennon y en particular una pareja Ono-Lennon que, con toda su carga de disi- 
denciay pensamiento-activismo revolucionario, suma puntos hasta ser un buen ejemplo de cómo es posible cumplir con los valores Ibero, con todo y sus inevitables fallas humanas.

El contexto general de esta experiencia formativa es que el ensayo funcione como la parte culminante del taller en su segmento de reflexión en temas libres, mediante una tarea de largo aliento y el procesamiento de sus resultados en clase, a fin de reafirmar, como algo vivo y operante en la vida cotidiana del inminente profesionista, los valores Ibero.

El diseño del ensayo tomó la forma de una investigación inducida, con bibliografía definida, toda ella con opciones de acceso en internet; elegí un concepto integrador que procesara el servicio de esta pareja a la sociedad: ombudsperson; seleccioné 10 valores a apreciar, facilitándolos a partir de una redacción casual en primera persona, a imitación de una voz estudiantil, y formulé una serie de preguntas para detonar el análisis.

Un segundo momento fue el debate en clase del tema a partir de los ensayos individuales. Mi rol al aplicar esta metodología fue retroalimentar con comentarios argumentales cada ensayo, así como diseñar y facilitar la discusión en clase. El formato de la tarea se presenta en la tabla siguiente: en la primera columna aparece el valor interpretado por mí, mientras que en la segunda se anota su correspondiente resolución Ibero.

Tabla 1

\section{MóDULO: TEORÍA PERSONALISTA DE EL/LA OMBUDSPERSONY EL EJEMPLO DE JOHN LENNON Y YOKO ONO}

REALIZAR UN ENSAYO EN CASA/DEBATE EN CLASE:

EN SU CONCEPTO DE FORMACIÓN INTEGRAL, LA IBERO TIENE LA FINALIDAD DE TRANSMITIR, ENTRE OTROS, LOS SIGUIENTES IO VALORES.

\begin{tabular}{|c|c|}
\hline Ser excelente en mi profesión u oficio. & $\begin{array}{l}\text { Excelencia académica; magis; competente, competitivo a nivel } \\
\text { internacional. }\end{array}$ \\
\hline $\begin{array}{l}\text { Ser una persona ética, que en las decisiones y situacionales que a } \\
\text { cada paso pone frente a mí la vida sepa distinguir y actuar por el } \\
\text { bien. También ser lo más posible coherente en las diferentes facetas } \\
\text { de mi vida. }\end{array}$ & $\begin{array}{l}\text { Persona cívica-social; de gran calidad humana; honestidad frente a la } \\
\text { corrupción; servir a la verdad. }\end{array}$ \\
\hline $\begin{array}{l}\text { Ser solidario para poder desprenderme de algo de lo que la vida me } \\
\text { dio la oportunidad de tener, y darlo a quienes no tuvieron esas } \\
\text { mismas oportunidades (ombudsperson). }\end{array}$ & $\begin{array}{l}\text { Hombres y mujeres para los demás; comprometidos en el mayor } \\
\text { servicio a los demás; compasión-compromiso; solidaridad, en } \\
\text { oposición al individualismo y la competencia. }\end{array}$ \\
\hline $\begin{array}{l}\text { Ser consciente de las situaciones de injusticia en la sociedad en que } \\
\text { vivo para, de manera participativa (activista), cambiarlas hacia un } \\
\text { mejor estado de la justicia social (ombudsperson). }\end{array}$ & $\begin{array}{l}\text { Agentes multiplicadores del cambio social al servicio del pobre y por } \\
\text { la justicia; conciencia social-compromiso; promoción de la justicia; } \\
\text { justicia, frente a tantas formas de injusticia y exclusión. }\end{array}$ \\
\hline $\begin{array}{l}\text { Ser realmente libre, lo más firmemente autodeterminado } \\
\text { en cualquier medio social en que me mueva. }\end{array}$ & Libertad, que posibilita la expresión total del ser humano. \\
\hline $\begin{array}{l}\text { Saber disfrutar la vida, sin caer en el consumismo irracional o } \\
\text { insultante (no ser manejado por lo material de la vida). }\end{array}$ & Sobriedad en oposición a un mundo basado en el consumismo. \\
\hline $\begin{array}{l}\text { Ser amoroso, amarse a uno mismo, amar al ser amado, amar a la } \\
\text { familia, amar a los demás, amar al mundo y la naturaleza, amor } \\
\text { como fuerza integradora que pone todo en armonía. }\end{array}$ & Amor en un mundo egoísta e indiferente. \\
\hline $\begin{array}{l}\text { Ser religioso con o sin "marca registrada" (alguna religión oficial), } \\
\text { en comunicación con el inexplicable trascendente que consuela y } \\
\text { proporciona una guía moral ante la vida. }\end{array}$ & Persona religiosa, vivencia de la fe. \\
\hline $\begin{array}{l}\text { Dejarme aleccionar por la vida para mi propia transformación } \\
\text { interior para ser una mejor persona. }\end{array}$ & $\begin{array}{l}\text { Conocimiento y transformación de la realidad personal (además de } \\
\text { la social); todo ser humano lleva en sí una potencialidad que le } \\
\text { trasciende y que siempre puede desarrollarse y crecer. }\end{array}$ \\
\hline
\end{tabular}

Especialmente hoy: empoderamiento de la mujer, no violencia hacia Género.

la mujer y equidad vivencial de género.

¿Quién es un ombudsperson? En sentido personalista y no institucional, este vocablo de origen sueco se refiere a aquel que defiende desinteresadamente la causa de otro en situación de injusticia o vulnerabilidad. Justiciero de a pie; le indigna que alguna persona, grupo, animal, naturaleza e incluso cosa sea tratada injustamente, lo que constituye su pasión por la justicia. Defensor motu proprio de causas justas. En nuestros días se asocia más con instituciones, como comisiones de derechos humanos y defensorías del pueblo, pero en su sentido amplio y original abarca desde personas y personajes reales, hasta personajes de ficción. 
Unas cuantas preguntas guía:

- ¿Hasta dónde llegó Lennon a hacer suyos estos valores Ibero y cuáles temas de los leídos o investigados te llamaron más la atención en él y con Yoko en pareja?

- ¿Qué hay de la pareja Ono-Lennon, y sobre todo del papel de ella en la relación?

- ¿Conocías este perfil integral de persona en este genio de la música rock?

- ¿Te gustaría decir algo sobre la música de los Beatles y John Lennon o sobre el rock y la música en general (opcional)?

- ¿Cuál sería tu ombudsperson favorito real o de ficción?

Fuente: Elaboración propia.

Los principales resultados de esta experiencia fueron entusiasmo y emotividad inusuales, traducidos en calidad, vitalidad y personalidad de los textos. En cuanto al debate en clase, una vez retroalimentado con mis subrayados y observaciones cada ensayo, hubo un gustoso deseo por participar. La dinámica en el aula incluyó la escucha de canciones de Lennon y la proyección de imágenes de la pareja, en ambos casos relacionadas con los valores analizados. También la afirmación del concepto ombudsperson, al requerir a cada uno sus personalidades y personajes favoritos (por ejemplo, Mandela, Malala Yousafzai, Batman y $\mathrm{V}$ de la película $V$ de venganza). El denominador común fue de asombro ante el desconocimiento de cómo una superestrella del rock y su pareja - socia artística y en gran medida educadora- hicieron tanto por el mundo, por su arte, por su amor de pareja y por sus propias personas.

Prácticamente todos coincidieron en afirmar que llevaban a cabo el conjunto de valores Ibero, con acento en la justicia social, solidaridad, crecimiento personal, amor, congruencia y, desde luego, excelencia profesional. En cuanto a la polémica, hubo algunas críticas, sobre todo con respecto a percibir a John con sospecha, como un revolucionario y partidario del feminismo por interés personal (manejo de imagen) y sin una clara desvinculación del machismo.

En particular, lo mejor de la experiencia fue que despertó una actitud investigativa antiburocrática y, sobre todo, que motivó al grupo a llegar al mundo profesional con los valores Ibero como lanza en ristre, a partir de asumirse como un o una ombudsperson. En cuanto a la utilidad, este módulo de John y Yoko se puede replicar en materias y talleres dentro y fuera de la universidad, en aulas reales y virtuales, con jóvenes y otros grupos de adultos. Y, más que eso, puede inspirar a que cada uno lo haga a partir de su propio conjunto de valores y sus ombudsperson referentes, según el medio sociocultural en que se mueva (deporte, empresa, religión, política, entre otros).

De forma ilustrativa, refiero ahora algunas narrativas escritas por los jóvenes talleristas:

A pesar de las amenazas que había en contra de Lennon, él nunca cedió ante la presión, ni ante las autoridades que lo querían fuera de la foto. Lo que más me impresionó y conmovió de la pareja JOhNO, es el apoyo que le dieron a tantas personas que lo necesitaban; a pesar del alto costo que sabían que podían pagar por seguir apoyando sus causas, jamás se detuvieron, y con los años sólo se hicieron más fuertes y mucho más influyentes. Fueron verdaderos líderes que difundieron paz y esperanza a miles de generaciones, de una forma artística y poética. (MB, Diseńo Industrial).

Se sabe que [John Lennon] era un rebelde que en su momento robó, se drogó y golpeó a las mujeres, creo que es fácil poder etiquetar a las personas por los errores que cometen en la juventud, hoy más que nunca con las imágenes que quedan plasmadas en las redes sociales, pero lo que más me gustó [...] fue que tomó responsabilidad sobre sus acciones $[. .$.$] y más por la manera en la$ que lo hizo, en el ojo público. Aquí es donde podemos comenzar a ver como supo amarse a sí mismo, con todo y errores, porque al final del día era un ser humano más. Fue capaz de transformarse en mejor persona. (CR, Comunicación).

El pasar a ser una persona así, a ser uno de los mayores defensores de los derechos de las mujeres
26 Cómo John y Yoko aplican los valores Ibero en su vida José Antonio Farías Hernández. DIDAC 79 (2022): 21-28 
es un triunfo brutal a mi parecer. (AC, Ingeniería Industrial).

John y Yoko, luchadores sociales, rebeldes empedernidos, revolucionarios hasta el tuétano, almas libres. (KG, Ingeniería Química).

[Sobre la] posibilidad de una nueva masculinidad [...], cómo él tuvo que romper con esquemas o aprendizajes para poder estar en una relación con una mujer que lo hacía crecer y que compartía su visión social; ella juega un papel esencial en la posibilidad de deconstruir y reconstruir su idea sobre las relaciones de pareja. (EG, Psicología).

Con su música y su vida, creo que John fue un verdadero guerrero nietzscheano; no uniforme ni estancado, sino cambiante, contradictorio (en buen sentido), y dispuesto a crear todo el tiempo nuevos valores. [...] Pues bien, me parece que no hay nada más nietzscheano que la transformación, que siempre implica una voluntad de poder; a saber, la voluntad de afirmar, de decir sí a la vida. (HS, Filosofía).

Espero lleno, lleno de esperanza y felicidad, que algún día una de las tantas semillas de valores que la Universidad sembró en cada uno de nosotros, crezca y genere unos resultados increíbles, dejando plasmada en la historia el nombre de la Universidad y su filosofía, así como John y Yoko dejaron su huella en la historia. (FT, Ingeniería Química).

Por último, desde luego que otros valores como la sustentabilidad, implícito en la relativa sobriedad de este matrimonio como estilo de vida, o la interculturalidad, como pareja birracial y en los sonidos multiétnicos de los Beatles, pueden trabajarse en el taller.

\section{ReferenCias}

Andrade, M. (2001). Un acercamiento a la problemática de la formación ciudadana. Ciudad de México: Universidad Iberoamericana.

Cano, A. (2012). La metodología de taller en los procesos de educación popular. Revista Latinoamericana de Metodología de las Ciencias Sociales, 2(2), 22-51. Recuperado de http://sedici.unlp.edu.ar/bitstream/handle/10915/ 26946/2223-3626-1-PB.pdf?sequence=1

Gadamer, H.G. (1977). Verdad y método. Salamanca: Sígueme.

Jesuitas. Provincia argentino-uruguaya. (2019). La pedagogía ignaciana en la educación superior jesuita. Recuperado de https://jesuitasaru.org/la-pedagogia-ignaciana-en-laeducacion-superior-jesuita/

Rorty, R. (1998). Derechos humanos, racionalidad y sentimentalidad, De los derechos humanos. Las conferencias Oxford amnesty de 1993. Madrid: Trotta.
Universidad Iberoamericana Ciudad de México. (1968). Ideario. Recuperado de http://tijuana.ibero.mx/quienessomos/ Ideario_IBERO2017.pdf

Universidad Iberoamericana Ciudad de México. (s. f.). Modelo educativo jesuita. Recuperado de https://ibero.mx/sites/all/ themes/ibero/descargables/acercade/piModelogeneral.pdf.

Universidad Iberoamericana Ciudad de México-Tijuana. (s. f.). Plan estratégico rumbo 2030. Recuperado de http://rumbo2030.ibero.mx/versionpdf.pdf

Universidad Iberoamericana Ciudad de México. (2021). Nuevos planes de estudio, una propuesta de la Ibero para hacer frente al futuro. Recuperado de https://ibero.mx/prensa/ nuevos-planes-de-estudio-una-propuesta-de-la-ibero-parahacer-frente-al-futuro

BiBLIOGRAFÍA RECOMENDADA

Alí, T. \& Blackburn, R. (1971). Entrevista de Tariq Ali y Robin Blackburn como colaboradores de Counter Punch. Recuperado de https://kaosenlared.net/entrevista-marxista-con-john-lennon-entrevista-de-1971/

El Círculo Beatle. (2019). John y Yoko, la entrevista de Playboy 1. Recuperado de https://elcirculobeatle.com/john-y-yokola-entrevista-de-playboy-1
Farías, J. A. (Coord.). (2007). Ombudsman. Filosofía, teoría y diversidad. Ciudad de México: CNDH.

Farías, J. A. (2020). San John Lennon: el Maestro en el cielo eterno del rock. Ciudad de México: Sextil Online/Ink It.

Leaf D. \& Scheinfeld J., (2006). The U. S. vs. John Lennon. Lionsgate, DVD. 


\section{SEMBLANZA}

Licenciado en Economía por la Universidad Nacional Autónoma de México (UNAM), maestro en Derechos Humanos y doctor en Ciencias Sociales y Políticas, ambos títulos por la Universidad Iberoamericana Ciudad de México. Ha publicado y coordinado artículos y libros. Entre sus publicaciones recientes están: "Los derechos humanos emergentes desde

la tradición social y su aproximación en el México actual” (Universidad Iberoamericana León); “Didácticas para el Servicio Social” (Universidad Iberoamericana Ciudad de México) y La tradición en politica y su valor como fundamento de los derechos humanos: históricos y emergentes (Universidad Iberoamericana Ciudad de México). Prepara un libro sobre la historia del servicio social en la Universidad Iberoamericana. Es profesor de tiempo completo en el Programa de Servicio Social Universitario de la Universidad Iberoamericana Ciudad de México.

\footnotetext{
${ }^{1}$ Naturalmente esto hace que algunos de los contenidos vayan cambiando cada semestre e incluso dentro de éste.

${ }^{2}$ Se trata de los textos: "Características de nuestra educación" (discurso en Georgetown, 1989), "Pedagogía Ignaciana: Un planteamiento práctico" (documento publicado por la Compañía de Jesús en 1993), "Servicio de la fe y promoción de la justicia" (conferencia dictada en Santa Clara, 2000), "Universidad y carisma ignaciano" (discurso en Monte Cucco, 2001) y "Al Consejo Directivo de la Universidad de Georgetown" (discurso ofrecido en Roma, 2007).

${ }^{3}$ Un primer aporte en esta línea se encuentra en DIDAC núm. 51 (nueva época, primavera 2008, Universidad Iberoamericana), con mi artículo: "Sentir los derechos humanos sin abrir la Declaración: un taller de reflexión".

${ }^{4}$ Disidentes, porque fueron contra el orden organizacional o institucional establecido al menos en arte, religión, familia y política. En este último caso, al disentir de los dogmas anarquistas, socialistas y comunistas de la necesidad de la revolución violenta para trasformar de raíz a la sociedad. Revolucionarios porque innovaron en el arte y las formas de la lucha política, además de sus procesos de transformación personal y como pareja. ${ }^{5}$ Este valor hace conexión con el transversal de la sustentabilidad.

${ }^{6}$ Este valor hace conexión con el transversal de la interculturalidad.
}

28 - Cómo John y Yoko aplican los valores Ibero en su vida José Antonio Farías Hernández. DIDAC 79 (2022): 21-28 